\title{
Actors in the Combodia Conflict, I975-I993
}

\begin{tabular}{|c|c|c|c|c|}
\hline & SOC & DK & FUNCINPEC & KPNLF \\
\hline \multirow[t]{4}{*}{$\begin{array}{l}\text { Governmental } \\
\text { identity }\end{array}$} & $\begin{array}{l}\text { People's Republic } \\
\text { of Kampuchea } \\
\text { (PRK) 1979-89 }\end{array}$ & $\begin{array}{l}\text { Democratic } \\
\text { Kampuchea } \\
\text { (Khmer Rouge) } \\
1975-82\end{array}$ & $\begin{array}{l}\text { United Front for } \\
\text { an Independent, } \\
\text { Neutral, Peaceful, } \\
\text { and Cooperative }\end{array}$ & $\begin{array}{l}\text { Khmer People's } \\
\text { National } \\
\text { Liberation Front } \\
\text { 1979-82 }\end{array}$ \\
\hline & $\begin{array}{l}\text { State of Cambodia } \\
1989-9.3\end{array}$ & $\begin{array}{l}\text { Coalition } \\
\text { Government }\end{array}$ & $\begin{array}{l}\text { Cambodia } \\
\text { (FUNCINPEC) } \\
1981-92\end{array}$ & CGDK 1982-90 \\
\hline & & $\begin{array}{l}\text { of Democratic } \\
\text { Kampuchea CGDK) } \\
1982-90\end{array}$ & CGDK 1982-90 & NGC 1990-93 \\
\hline & & $\begin{array}{l}\text { National } \\
\text { Government } \\
\text { of Cambodia (NGC) } \\
\text { 1990-93 }\end{array}$ & NGC 1990-93 & \\
\hline \multirow[t]{2}{*}{ Party identity } & $\begin{array}{l}\text { Cambodian } \\
\text { People's } \\
\text { Party 1991- }\end{array}$ & $\begin{array}{l}\text { Party of Democratic } \\
\text { Kampuchea (PDK) } \\
1976\end{array}$ & $\begin{array}{l}\text { FUNCINPEC } \\
1981\end{array}$ & $\begin{array}{l}\text { Buddhist Liberal } \\
\text { Democratic Party } \\
\text { (BLDP) 1992- }\end{array}$ \\
\hline & $\begin{array}{l}\text { Khmer People's } \\
\text { Revolutionary } \\
\text { Party (KPRP) } \\
\text { 1979-91 }\end{array}$ & $\begin{array}{l}\text { Communist Party } \\
\text { of Kampuchea } \\
\text { (CPK) } \\
1960-81 \text { (secret) }\end{array}$ & & \\
\hline \multirow[t]{2}{*}{ Leaders } & $\begin{array}{l}\text { Hun Sen, } \\
\text { prime minister }\end{array}$ & $\begin{array}{l}\text { Khieu Samphan } \\
\text { (foreign affairs) }\end{array}$ & $\begin{array}{l}\text { Prince Sihanouk } \\
\text { (former chief } \\
\text { of state) }\end{array}$ & $\begin{array}{l}\text { Son Sann } \\
\text { (former prime } \\
\text { minister) }\end{array}$ \\
\hline & $\begin{array}{l}\text { Heng Samrin, } \\
\text { president } \\
\text { of PRK }\end{array}$ & $\begin{array}{l}\text { Pol Pot ("brother } \\
\text { number one") } \\
\text { Ieng Sary } \\
\text { (China relations) }\end{array}$ & $\begin{array}{l}\text { Prince Ranariddh } \\
\text { (son) }\end{array}$ & \\
\hline $\begin{array}{l}\text { Regional } \\
\text { supporters }\end{array}$ & $\begin{array}{l}\text { Socialist Republic } \\
\text { of Vietnam(SRV) }\end{array}$ & $\begin{array}{l}\text { Thailand (covert } \\
\text { border traffic) } \\
\text { China (arms supply) }\end{array}$ & $\begin{array}{l}\text { ASEAN (Brunei, } \\
\text { Indonesia. } \\
\text { Malaysia, } \\
\text { Philippines, } \\
\text { Singapore, ) } \\
\text { Thailand }\end{array}$ & ASEAN \\
\hline $\begin{array}{l}\text { Aligned } \\
\text { outside } \\
\text { powers }\end{array}$ & ${ }^{\circ}$ USSR & ${ }^{\circ}$ China 1975-92 & $\begin{array}{l}\text { Australia, } \\
{ }^{\circ} \text { France, Japan, } \\
{ }^{\circ} \text { USA, }{ }^{\circ} \text { UK }\end{array}$ & $\begin{array}{l}\text { Australia, } \\
{ }^{\circ} \text { France, Japan, } \\
{ }^{\circ} \mathrm{USA},{ }^{\circ} \mathrm{UK}\end{array}$ \\
\hline
\end{tabular}

'USSR (Russia), China, France, UK, and USA confer monthly starting January 1990, as permanent members of UN Security Council, P-5. 
